\title{
Extraction and analysis of carotenoids from the New Zealand sea urchin Evechinus chloroticus gonads*
}

\author{
Daniel Garama ${ }^{1 凶}$ Phil Bremer $^{2}$ and Alan Carne ${ }^{1}$ \\ 1Department of Biochemistry, University of Otago, Dunedin, New Zealand; 2Department of Food Science, University of Otago, Dunedin, New \\ Zealand
}

Sea urchin gonad (roe) is a highly valued food in Japan and North America. Gonad price is strongly influenced by quality, with appearance, especially colour being a major determinant. Previous attempts to extract a carotenoid profile from the New Zealand sea urchin species Evechinus chloroticus have been challenging due to the large amount of lipid present in the gonad. A carotenoid extraction and high performance liquid chromatography (HPLC) analysis method was developed to reduce lipid contamination by incorporating a saponification and lipid cold precipitation in the extraction procedure. This method enabled greater carotenoid purity and enhanced analysis by HPLC. Echinenone was found to be the main carotenoid present in all E. chloroticus gonads. Dark coloured gonads contained higher levels of fucoxanthin/ fucoxanthinol, $\beta$-carotene and xanthophylls such as astaxanthin and canthaxanthin. This information on the modification and deposition of carotenoids will help in the development of diets to enhance gonad colour.

Key words: Evechinus chloroticus, sea urchin gonad, carotenoid extraction and analysis, carotenoid extract lipid contamination

Received: 17 October, 2011; accepted: 01 March, 2012; available on-line: 17 March, 2012

\section{INTRODUCTION}

Sea urchin gonads (roe) are a highly valued food with factors such as appearance, texture, flavour and most importantly colour strongly influencing their desirability and price in the international market (Unuma et al., 2002; Symonds, 2007). New Zealand shorelines contain an abundant supply of the native sea urchin species Evechinus chloroticus Valenciennes (Echinoidea:Echinometridae). However, the development of an export market for this species is limited by their variable gonad colour, which ranges from a desirable yellow/orange to an undesirable brown/black (McShane et al., 1994; Phillips 2009a; $2009 \mathrm{~b} ; 2009 \mathrm{c})$. There is therefore considerable interest in the establishment of a sea urchin aquaculture system to enhance the quality of sea urchin gonad that are of inconsistent quality and currently under utilised (Keesing \& Hall, 1998; Kelly, 2001; Liyana-Pathirana et al., 2002).

It has previously been reported that both the gonad yield (Barker, 2001; McBride et al., 2004; James, 2006a; 2006b) and the sensory quality (Phillips, 2009a; 2009b; 2009c) of E. chloroticus can be enhanced by holding sea urchins in sea cages or land-based systems and feeding them for 8 to 12 weeks. Previous attempts to enhance E. chloroticus gonad colour through diet modification have been met with limited success, due in part to a poor understanding of how carotenoids are involved in gonad colour development. It is postulated that a better understanding of carotenoid content and metabolism will aid in the development of diets designed to enhance the colour, quality and value of the New Zealand sea urchin resource.

Sea urchin gonad colour is thought to be due to carotenoids and carotenoid precursors obtained from the diet, which are either modified and deposited or directly deposited in the gonad tissue (Galasko et al., 1969; Hora et al., 1970; Tsushima \& Matsuno, 1990; Symonds, 2007; Symonds, 2008). Echinenone and $\beta$-carotene have been identified as the most abundant carotenoids present in the gonad of 11 different species of sea urchins around the world (Tsushima \& Matsuno, 1990). While many edible sea urchin species have been analysed for carotenoid content, limited information is available on E. chloroticus due to the presence of interfering compounds, such as lipids in the gonad (Liyana-Pathirana et al., 2007), preventing the recovery of highly purified carotenoid extracts.

The goal of the current study was to develop an efficient method for extracting, separating and analysing carotenoid compounds from tissues rich in lipid, such as E. chloroticus gonads, and to determine the carotenoid profile for male and female, light and dark coloured E. chloroticus gonads.

\section{METHODS}

Sea urchin collection. Sea urchins (E. chloroticus) from Doubtful Sound, Fiordland (New Zealand) were transported in seawater at $15^{\circ} \mathrm{C}$ to the Portobello Marine Laboratory, University of Otago within $24 \mathrm{~h}$ of collection. The sea urchins were placed into tanks supplied with flowing seawater and fed Macrocystis pyrifera (kelp) until required.

Dissection. To recover the gonads an incision was made in the peristomal membrane of the urchin and the coelomic fluid drained. The test was separated into two halves and the gut and gonads removed and weighed. The gender of each urchin was determined by examining a wet-squash preparation of fresh gonad tissue in a drop of seawater using phase-contrast light microscopy, as previously described by Kelly (2001) to detect the presence of either sperm or eggs.

Colour assessment. Visual colour assessment of the gonads was carried out under standard light conditions using universal colour standard charts as previously

e-mail: daniel.garama@otago.ac.nz

* Presented at the 16th International Symposium on Carotenoids, 17-22 July, 2011, Kraków, Poland 

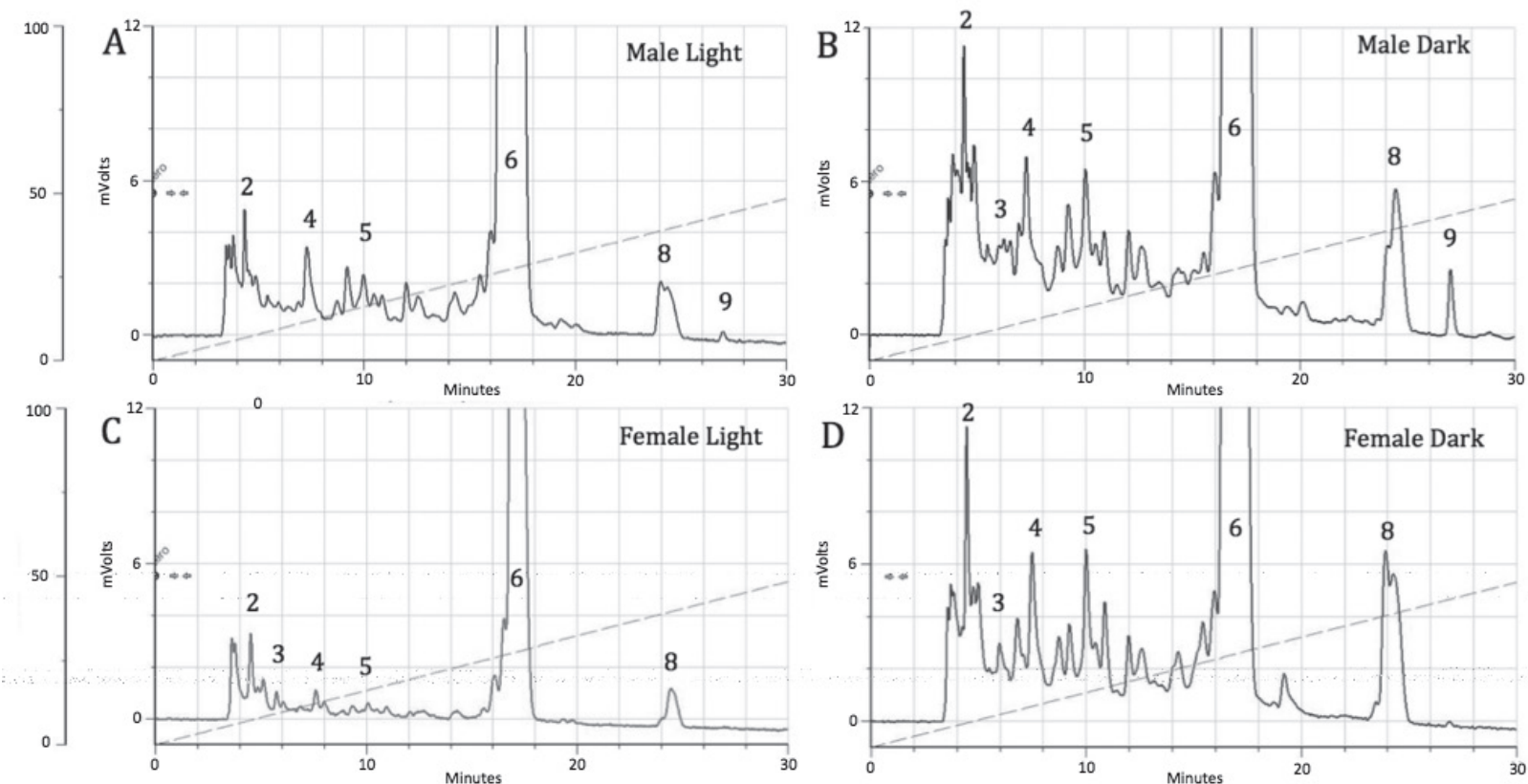

Figure 1. Representative HPLC chromatograms of (A) light male, (B) dark male, (C) light female and (D) dark female gonad caroteniods from E. chloroticus.

Homogeneous gonads ( $1 \mathrm{~g}$ wet weight) were homogenised in AR acetone. Carotenoids were separated from saponified lipids, evaporated to dryness and reconstituted in AR methanol. Remaining lipids were cold precipitated, supernatants filtered and aliquots analysed on a Phenomenex C18 column by gradient HPLC. Carotenoids identified were fucoxanthinol (2), violaxanthin (3), astaxanthin (4), canthaxanthin (5), echinenone (6), $\beta$-carotene (8) and a-carotene (9) based on the retention times of commercial standards.

described by Symonds et al. (2008). Gonad colour was rated as being 'light' (yellow-orange) or 'dark' (brownblack).

Carotenoid extraction. To extract the carotenoids, freshly excised gonads were rinsed in filtered $(0.45$ $\mu \mathrm{m}$ cellulose Acrodisc $^{\circledR}$ membrane filter, PALL Life Sciences) seawater to remove any foreign debris. Gonad tissue (1 g total wet weight) was homogenised in AR acetone $(1: 1, \mathrm{w} / \mathrm{v})$ using a Du-Pont Omni-mixer (USA) under red light conditions to minimise photo-oxidation of carotenoids. The homogenate was transferred to a $15 \mathrm{~mL}$ amber tube and centrifuged at $6000 \times g$ for $30 \mathrm{~min}$ at $4^{\circ} \mathrm{C}$. The liberated carotenoid compounds in the supernatant were transferred to a $15 \mathrm{~mL}$ amber vial and evaporated to dryness with oxygen-free nitrogen. The residue was reconstituted in $2 \mathrm{~mL}$ AR diethyl ether and $2 \mathrm{~mL}$ of $10 \%$ methanolic potassium hydroxide and left overnight to saponify the lipids present in the residue. After saponification, $4 \mathrm{~mL} 5 \%$ sodium chloride was added and the vial was flushed with oxygen free $\mathrm{N}_{2}$ and shaken vigorously for $5 \mathrm{~min}$ and left to phase separate. Carotenoid compounds were removed from the upper solvent phase, placed into an amber microcentrifuge tube and evaporated to dryness using a Savant SpeedVac. Carotenoid residues were reconstituted in HPLC grade methanol and cooled on dry ice for 10 min allowing remaining lipid contamination to precipitate. Samples were centrifuged at $10000 \times g$ for $30 \mathrm{sec}$ at $-4^{\circ} \mathrm{C}$ and the supernatant filtered with a $0.2 \mu \mathrm{m}$ GHP (G-hydrophillic polypropylene) Acrodisc ${ }^{\circledR}$ membrane filter (PALL Life Sciences) into amber microcentrifuge tubes. All procedures were carried out under red light and oxygendepleted conditions to minimise oxidation of carotenoid compounds.

Carotenoid analysis. Reversed-phase high performance liquid chromatography (HPLC) was carried out using a C18 Phenosphere column (5 $\mu \mathrm{m}$,
$250 \times 4.6 \mathrm{~mm}$, Phenomenex, UK) combined with a guard column (Security guard, Phenomenex, UK). Solvents were delivered using a binary pump system (321 series, Gilson, USA) and consisted of methanolwater $(99: 1 \%)$ containing $0.2 \% \quad(\mathrm{v} / \mathrm{v})$ ammonium acetate (solvent A) and tert-butyl methyl ether (100\%) (solvent B) at a flow rate of $1 \mathrm{~mL} \cdot \mathrm{min}^{-1}$ as previously described by Symonds, et al. (2007). Carotenoids were detected in the HPLC effluent at 447 and $474 \mathrm{~nm}$ using a UV detector (156 series, Gilson USA). Each gonad carotenoid extract and HPLC analysis was repeated at least four times.

Carotenoids were identified by retention time (tR) and absorption spectrum $\left(\lambda_{\max }\right.$ and spectral shape) compared to the commercial standards echinenone, $\alpha$-carotene $(\beta, \varepsilon$-carotene $), \quad \beta$-carotene $(\beta, \beta$-carotene), astaxanthin, violaxanthin and fucoxanthin obtained from DHI (Denmark).

\section{RESULTS}

Carotenoid profiles were determined from both light (yellow/orange) and dark (brown/black), male and female sea urchin gonads. All of the light and dark gonads analysed had similar carotenoid profiles to the other gonads classified as being either light or dark (Fig. 1). A total of seven carotenoids were identified from the profiles based on retention times of commercial standards. In all of the gonads analysed (light and dark, male and female), echinenone ( $\sim 88 \mu \mathrm{g} / 1 \mathrm{~g}$ wet weight) was the dominant carotenoid accounting for over $80 \%$ of the total extractable carotenoid. Comparisons between male and female gonad carotenoid profiles revealed a single consistent variation, with male gonads containing slightly increased levels of alpha carotene compared to female gonads. 
Dark coloured gonads of both sexes contained greater amounts of the minor xanthophyl carotenoids than light coloured gonads, with the greatest increase being fucoxanthinol $(2 \mu \mathrm{g} / 1 \mathrm{~g}$ wet weight) followed by $\beta$-carotene $(1 \mu \mathrm{g} / 1 \mathrm{~g}$ wet weight), astaxanthin $(1 \mu \mathrm{g} / 1$ $\mathrm{g}$ wet weight) and canthaxanthin $(1 \mu \mathrm{g} / 1 \mathrm{~g}$ wet weight). A number of other carotenoid compounds also appeared to increase in the dark tissue, however due to the lack of appropriate standards these compounds were unable to be identified.

\section{DISCUSSION}

It was found that the lipid present in the E. chloroticus gonads could be removed by the addition of a centrifugation step followed by temperature precipitation after saponification. These additional steps improved the quality and purity of the carotenoid extract and enhanced separation and the life of the HPLC column.

The observed minimal variation between the carotenoid profile of male and female E. chloroticus gonad is consistent with previous reports for Psammechinus miliaris (Symonds et al., 2007) and Paracentrotus lividus (Shipigel et al., 2004). Echinenone the most dominant carotenoid present in all E. chloroticus sea urchin gonad, is not present in the seaweed that comprises the major component of the urchins diet as previously reported for other sea urchin species (Kawakami et al., 1998, Robinson et al., 2002; Symonds et al., 2007). It is postulated that echinenone is metabolised from dietary $\beta$-carotene and either preferentially transported to, or stored in the gonad in much greater concentrations than the other carotenoids, where it may play a role in sea urchin reproduction (Tsushima \& Matsuno, 1997).

The dark coloured gonad of both sexes contained increased amounts of the carotenoid precursor, $\beta$-carotene and other minor xanthophylls such as astaxanthin and canthaxanthin compared to the light coloured gonad. Their increased amounts suggest that they may be impacting on gonad colour. Minor xanthophyll carotenoids can be relatively easily produced as they are metabolised from $\beta$-carotene (Britton, 1995; Symonds et al., 2007), however their presence in the gonad may be due to direct deposition from a dietary source.

Fucoxanthinol is also present in higher amounts in male and female dark coloured gonads compared to light coloured gonads. Fucoxanthinol and its unstable precursor fucoxanthin are the brown carotenoids present in high concentrations in the brown seaweed, which is the main diet of many sea urchin species (Symonds et al., 2008). It is thought that these carotenoids are too complex to be metabolised from the available dietary precursors and are therefore directly deposited to the gonad. It is unclear why they are present in increased amounts in dark coloured gonad and the impact they have on roe colour.

\section{Acknowledgements}

Funding for this research was provided by the New Zealand Foundation for Research, Science, and Technology.

\section{REFERENCES}

Barker MF, Keogh JA, Lawrence JM, Lawrence AL (1998) Feeding rate, absorption efficiencies, growth, and enhancement of gonad production in the New Zealand sea urchin Evechinus chloroticus Valenciennes (Echinoidea:Echinometridae) fed prepared and natural diets. J Shellfish Res 17: 1583-1590.
Barker MF (2001) Edible Sea Urchins: Biology and Ecology. The ecology of Evechinus chloroticus. Lawrence JM, eds, pp 245-261. Elsevier Science, Amsterdam.

Britton G (1995) Structure and properties of carotenoids in relation to function. J Fed Am Soc Exp Biol 9: 1551-1558.

Galasko G, Hora J, Toube T, Weedon B, Andre D, Barbier M, Lederer E, Villanueva V (1969) Carotenoids and related compounds. Part XXII. Allenic carotenoids in sea urchins. I Chem Soci C: 1264-1265.

Hora J, Toube TP, Weedon BCL (1970) Carotenoids and related compounds. Part XXVII. Conversion of fucoxanthin into paracentrone. J Chem Soc C: 241-242.

James PJ (2006a) A comparison of roe enhancement of the sea urchin Evechinus chloroticus in sea-based and land-based cages. Aquaculture 253: $290-300$.

James PJ (2006b) The effects of wave and feeding disturbance on roe enhancement of the sea urchin Evechinus chloroticus held in sea-cages. Aquaculture 252: 361-371.

James PJ, Heath PL (2008) Long term roe enhancement of Evechinus chloroticus. Aquaculture 278: 89-96.

Keesing JK, Hall KC (1998) Review of harvests and status of world sea urchin fisheries points to opportunities for aquaculture. $J$ Shellfish Research 17: 1597-1604.

Kelly MS (2001) Environmental parameters controlling gametogenesis in the echinoid Psammechinus miliaris. J Exp Marine Biol Ecol 266: 67-80.

Lamare M, Hoffman J (2004) Natural variation of carotenoids in the eggs and gonads of the echinoid genus, Strongylocentrotus: implications for their role in ultraviolet radiation photoprotection. J Exp Marine Biol Ecol 312: 215-232.

Lawrence J (2001) Edible Sea Urchins: Biology and Ecology. Elsevier, Amsterdam.

Livana-Pathirana C, Shahidi F, Hooper F (2007) Lipid and lipid soluble components of gonads of green sea urchin (Strongylocentrotus droebachiensis). J Food Lipids 9: 105-126.

Liyana-Pathirana C, Shahidi F, Whittick A, Hooper R (2002) Effect of season and artificial diet on amino acids and nucleic acids in gonads of green sea urchin Strongylocentrotus droebachiensis. Comp Biochem Physiol. Part A, Mol \& Integ Physiol 133: 389-398.

McBride S, Price R, Tom P, Lawrence J, Lawrence A (2004) Comparison of gonad quality factors: colour, hardness and resilience, of Strongylocentrotus fransiscanus between sea urchins fed prepared feed or algal diets and sea urchins harvested from the Northern California fishery. Aquaculture 233: 405-422

McShane P, Anderson O, Gerring P, Stewart R, Naylor J (1994) Fisheries biology of Kina (Evechinus chloroticus). Ministry of Agriculture and Fisheries, Wellington, New Zealand (New Zealand Fisheries Assessment Research Document 94/17).

Phillips K, Niimi J, Hamid N, Silcock P, Delahunty C, Barker M, Sewell M, Bremer P (2009a) Sensory and volatile analysis of sea urchin roe from different geographical regions in New Zealand. Food Sci Technoly 243: 202-213.

Phillips K, Hamid N, Silcock P, Delahunty C, Barker M, Bremer P (2009b) Effect of season on the sensory quality of sea urchin (Evechinus chloroticus) roe. J Food Sci 75: 20-30.

Phillips K, Bremer P, Silcock P, Hamid N, Delahunty C, Barker M, Kissick J (2009c) Effect of gender, diet and storage time on the physical properties and sensory quality of sea urchin (Evechinus chloroticus) gonads. Aquaculture 288: 205-215.

Shpigel M, Schlosser S, Ben-Amotz A, Lawrence A, Lawrence J (2005) Effects of dietary carotenoid on the gut and gonad of the sea urchin Paracentrotus lividus. Aquaculture. 261: 1269-1280.

Symonds R, Kelly M, Caris-Veyrat C, Young A (2007) Carotenoids in the sea urchin Paracentrotus lividus: Occurrence of 9'-cis-echinenone as the dominant carotenoid in gonad colour determination. Comp Biochem Physiol Part B: Biochem Mol Biol 148: 432-444.

Symonds R, Kelly M, Suckling C, Young A (2009) Carotenoids in the gonad and gut of the edible sea urchin Psammechinus miliaris. Aquaculture 288: 120-125.

Robinson S, Castell J, Kennedy E (2002) Developing suitable colour in the gonads of cultured green sea urchins (Strongylocentrotus droebachiensis) fed diets. Aquaculture 206: 289-303.

Tsushima M, Matsuno T (1990) Comparative biochemical studies of carotenoids in sea urchins. Comp Biochem Physiol 96B: 801-810.

Unuma T, Nakamura A, Yamano K, Yokota Y (2010) The sea urchin major yolk protein is synthesized mainly in the gut inner epithelium and the gonadal nutritive phagocytes before and during gametogenesis. Mol Rep Dev 77: 59-68. 
